\title{
MODELLING SNOW ACCUMULATION AND SNOW MELT IN A CONTINUOUS HYDROLOGICAL MODEL FOR REAL-TIME FLOOD FORECASTING
}

\author{
Philipp Stanzel, Ulrich Haberl, Hans-Peter Nachtnebel \\ Institute of Water Management, Hydrology and Hydraulic Engineering, University of Natural \\ Resources and Applied Life Sciences \\ Vienna, Austria \\ philipp.stanzel@boku.ac.at
}

\begin{abstract}
Hydrological models for flood forecasting in Alpine basins need accurate representation of snow accumulation and snow melt processes. A continuous, semidistributed rainfall-runoff model with snow modelling procedures using only precipitation and temperature as input is presented. Simulation results from an application in an Alpine Danube tributary watershed are shown and evaluated with snow depth measurements and MODIS remote sensing snow cover information. Seasonal variations of runoff due to snow melt were simulated accurately. Evaluation of simulated snow depth and snow covered area showed strengths and limitations of the model and allowed an assessment of input data quality. MODIS snow cover images were found to be valuable sources of information for hydrological modelling in alpine areas, where ground observations are scarce.
\end{abstract}

Keywords: snow modelling, rainfall-runoff modelling, flood forecasting, alpine hydrology, MODIS snow cover data.

\section{INTRODUCTION}

In alpine basins snow melt can contribute severely to flood runoff. Thus modelling snow melt accurately is of central importance to flood forecasting. In order to provide adequate system states for all flood events the processes of snow accumulation and snow melt need to be simulated continuously.

Snow modelling generally faces problems of snow data scarcity. Snow depth is measured at many stations, but mostly in the valleys, and snow density and snow water equivalent are not measured regularly. Available snow measurements typically are not transmitted in real-time and therefore cannot be used as input for real-time flood forecasting. The same applies to measurements of radiation, which could be used in snow modelling algorithms. Though precipitation measurements are known to have considerable errors especially in winter, they are, together with temperature measurements, commonly the only available input for the simulation of snow system states in the context of real-time flood forecasting.

The presented contribution shows results of snow modelling with a continuous hydrological model in the context of a real-time flood forecasting system in an alpine Danube tributary basin. Simulation results were evaluated using discharge measurements and snow depth measurements. In addition to ground measurements 
MODIS remote sensing snow cover data was tested as a means for hydrological model validation.

\section{SNOW MODEL}

The applied snow model is part of the continuous, semi-distributed rainfall-runoff model COSERO, developed at the Institute of Water Management, Hydrology and Hydraulic Engineering. Processes of snow accumulation and snow melt are calculated for hydrological response units (HRUs) derived from intersection of maps of subbasin boundaries, soil types, land cover and $200 \mathrm{~m}$ elevation bands.

Only precipitation and temperature are needed as input. Separation of precipitation into rainfall and snowfall is effected with two threshold temperatures. Snowfall is distributed to five internal snow classes with a log-normal distribution to consider variable snow-depths within a HRU. Snow melt is simulated with a temperature-index approach with spatially distributed, seasonally varying melt factors. Higher reflection of fresh snow is considered by a reduction of the melt-factor after the snowfall event. The model also accounts for evaporation from snow, retention of liquid water in the snow pack, refreezing of retained liquid water, and settling of the snow layer (Fuchs, 1998). Glacier areas are considered as deep snow layers.

Subsequently, the transformation of rainfall and melt water to runoff is effected in a conceptual model accounting for processes of infiltration, soil storage, runoff generation and routing. Separation of runoff into fast surface runoff, inter flow and base flow is calculated by means of a cascade of linear and non-linear reservoirs (Nachtnebel et al., 1993).

The model is calibrated against measured catchment runoff with historic time series of precipitation and temperature as input data. Initial model parameters are based partly on physical meaning and partly on previous experiences. Only few of the snow model parameters are adjusted in a manual calibration procedure. Values of minimum and maximum melt factors which determine the sine shaped seasonal course of the snow melt factor are altered. Their spatial patterns, based on radiation patterns (Kling, 2006), are kept constant. Threshold temperatures for snowfall and snow melt and a parameter governing snow depth variability are less influential and modified within close constraints.

\section{APPLICATION}

The model was implemented in a flood forecasting application in the Salzach basin, an Alpine Danube tributary watershed. The presented results were obtained in its most upstream part, where the influence of snow melt on runoff is highest. This catchment from the source to the gauge in Mittersill has an area of $600 \mathrm{~km}^{2}$, with altitudes ranging from 800 to $3600 \mathrm{~m}$ a.s.l. (Figure 1). It was divided into 10 subcatchments and $251 \mathrm{HRUs}$ with sizes ranging from $0,05 \mathrm{~km}^{2}$ to $14 \mathrm{~km}^{2}$.

The model was pre-calibrated with precipitation and temperature data regionalized from daily ground measurements from 1999 to 2005. Runoff simulation results on a 
daily basis were evaluated for the period from 1995 to 1998 . For the period from 2003 to 2005 hourly precipitation analyses incorporating ground and radar measurements of the Central Institute for Meteorology and Geodynamics (ZAMG) were available. They are based on comparable algorithms as the input for operational flood forecasting and were used as definitive input for calibration. Simulation results presented were derived with these input data. The meteorological analyses have a spatial resolution of a $1 \times 1 \mathrm{~km}$ grid and a temporal resolution of one hour. The algorithms for this product (Haiden, 2007) were revised within this project in joint hydrological and meteorological research. A general increase of the amount of snowfall of $30 \%$ was applied.

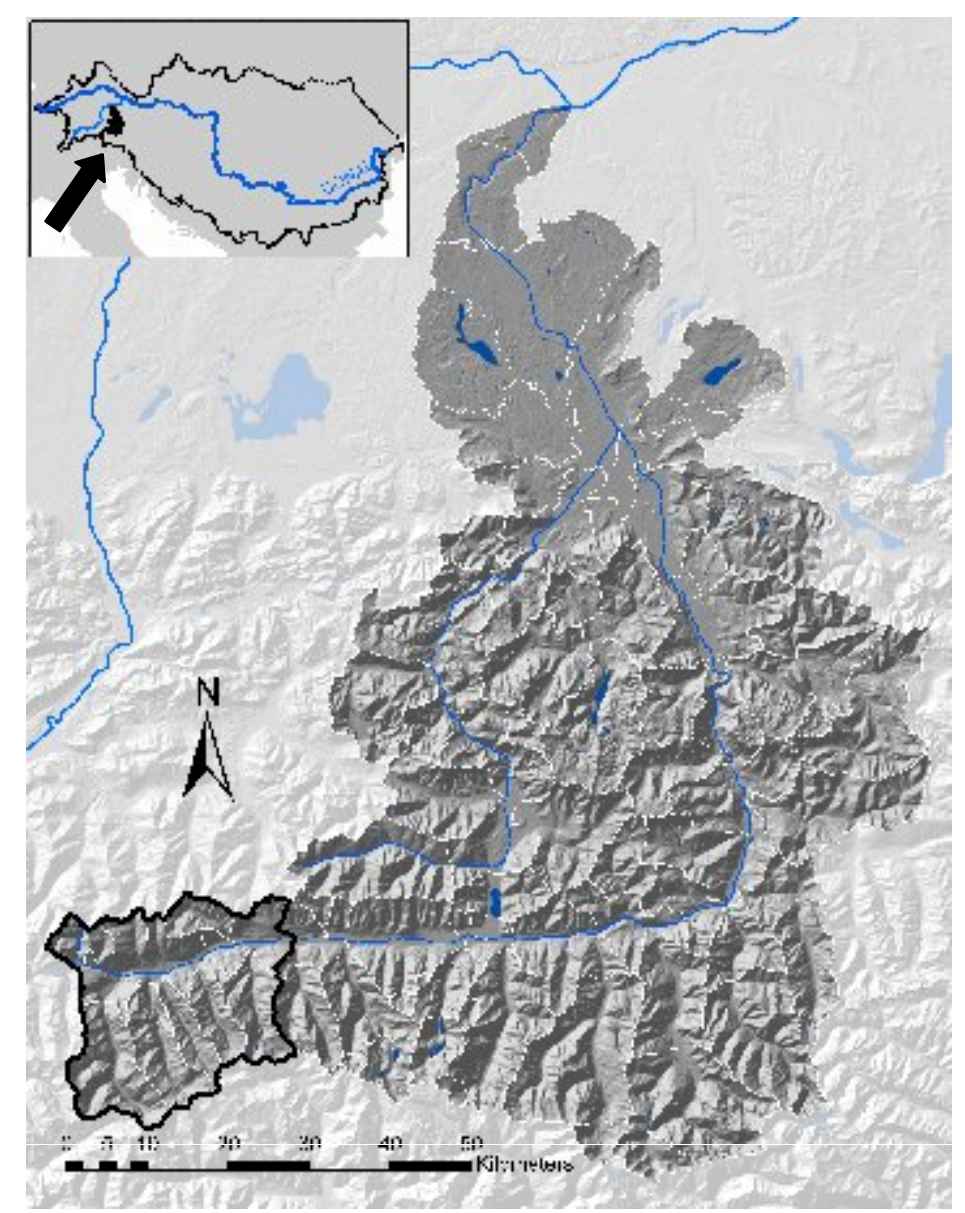

Figure 1: Map of Salzach basin and subbasin Mittersill

\section{SNOW DATA}

\subsection{Snow depth measurements}

Snow depth measurements from 11 meteorological stations in and around the catchment area were obtained (Figure 2). Most stations are located at elevations between 800 and $1500 \mathrm{~m}$ a.s.l., with only 2 stations at approximately $2300 \mathrm{~m}$ a.s.l. In the later ablation period, when only higher areas are snow covered, only these two stations provided ground based information. 


\subsection{MODIS snow cover data}

MODIS (Moderate Resolution Imaging Spectroradiometer) is an instrument aboard the two satellites of NASA Earth Observation System, Terra and Aqua. MODIS observations are processed at the U.S. National Snow and Ice Data Center (NSIDC) to obtain daily snow cover data grids with a resolution of $500 \times 500 \mathrm{~m}$. The general applicability of MODIS snow cover images for the evaluation of snow covered area in Austria was shown by Parajka and Blöschl (2006).

For two snow melt periods in 2004 and 2005 MODIS snow cover products (MOD10A1, Version 4 and 5) were downloaded from the NSIDC Distributed Active Archive Center (DAAC). For each year three snow cover maps with the least cloud cover interference were selected (Hall et al., 2006).

Figure 2 shows the snow cover map of 02.05 .2005 . It can be seen that frequently the edges of snow-covered area are mapped as clouds, a general deficiency of the actual MODIS algorithm. For analysis the area classified as snow was interpreted as minimal snow cover extent, this area plus the area classified as cloud as maximal snow cover extent. As only maps of generally days with very little cloud cover were analysed, this approach lead to rather narrow ranges of snow covered area.

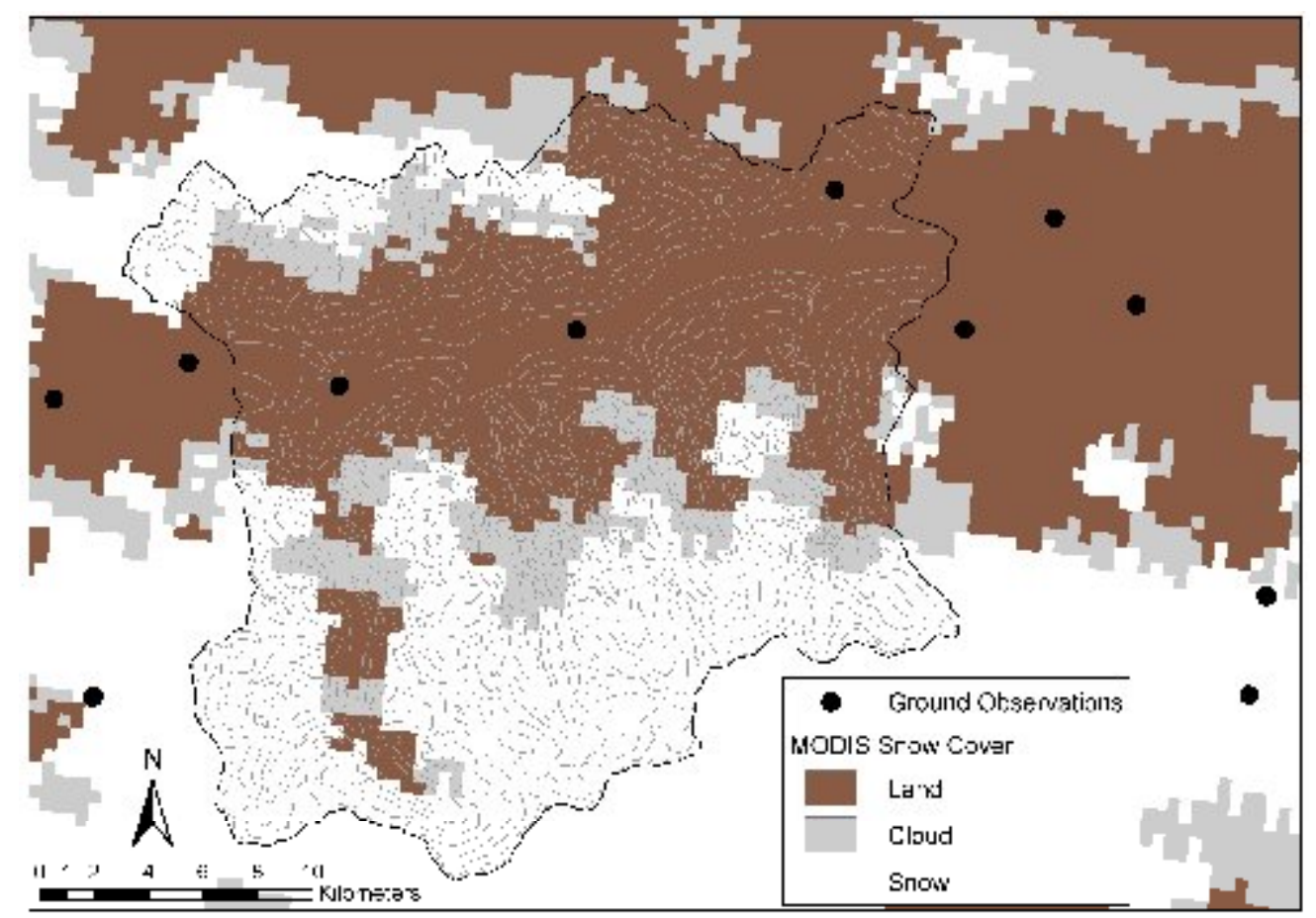

Figure 2: MODIS Snow cover map (02.05.2005) and ground observation points

\subsection{Comparison of ground observations and MODIS images}

Table 1 shows a comparison of ground observations of snow cover (snow depth larger than $1 \mathrm{~cm}$ ) and MODIS snow classification for the corresponding pixel. The agreement for both evaluation periods was generally good. While in 2004 the decrease of snow covered area as measured by MODIS was faster than measured on the ground (with one station pixel misclassified as not snow covered), the 
decrease in 2005 was slower as measured by MODIS than measured on the ground (with two and then one station pixel misclassified as snow covered).

Table 1: Snow cover measurements - ground observations and MODIS classification for the pixel corresponding with the location of the ground observation

\begin{tabular}{lcc}
\hline $\begin{array}{l}\text { Total nr. of ground } \\
\text { observations: }\end{array}$ Date & $\begin{array}{c}\text { Nr. of ground } \\
\text { observations } \\
\text { snow }\end{array}$ & $\begin{array}{c}\text { MODIS } \\
\text { classification } \\
\text { snow }\end{array}$ \\
\hline 30.04 .2004 & 2 & 2 \\
08.06 .2004 & 2 & 1 \\
17.06 .2004 & 2 & 1 (Cloud) \\
15.03 .2005 & 11 & 11 \\
22.04 .2005 & 3 & 5 \\
02.05 .2005 & 2 & 3 \\
\hline
\end{tabular}

\section{RESULTS AND DISCUSSION}

\subsection{Evaluation of simulation results}

Snow modelling results - after a calibration based on runoff only - were evaluated in three ways. Simulated runoff in snow melt periods was compared with measured runoff in Mittersill. Simulated snow depths were averaged for elevation bands and compared with measurements of stations located within the corresponding elevation range. Simulated snow covered area was averaged for elevation bands and compared with snow covered area shown by MODIS snow cover maps.

Results of runoff simulations are shown in Figure 3. The seasonal runoff variations due to snow melt processes are well represented. For the simulation from October 2003 to October 2005 a Nash-Sutcliffe coefficient of 0,88 was achieved. The water balance indicated precipitation deficits of $4 \%$ for 2004 and $10 \%$ for 2005 (which is also clearly visible in the hydrograph of summer 2005).

Simulated snow depths were generally lower than measurements. Figure 4 shows results for the elevation band $900-1100 \mathrm{~m}$ a.s.I. in comparison with two stations at corresponding elevations. Similar results were obtained for other elevations. Differences between measured and simulated snow depths can stem from differences between assumed and real snow densities. At the end of the accumulation period, when snow has settled, these discrepancies should be low, however. These results suggest that there is still some underestimation of precipitation in the input data in the snowfall period, despite the included increase of $30 \%$. 

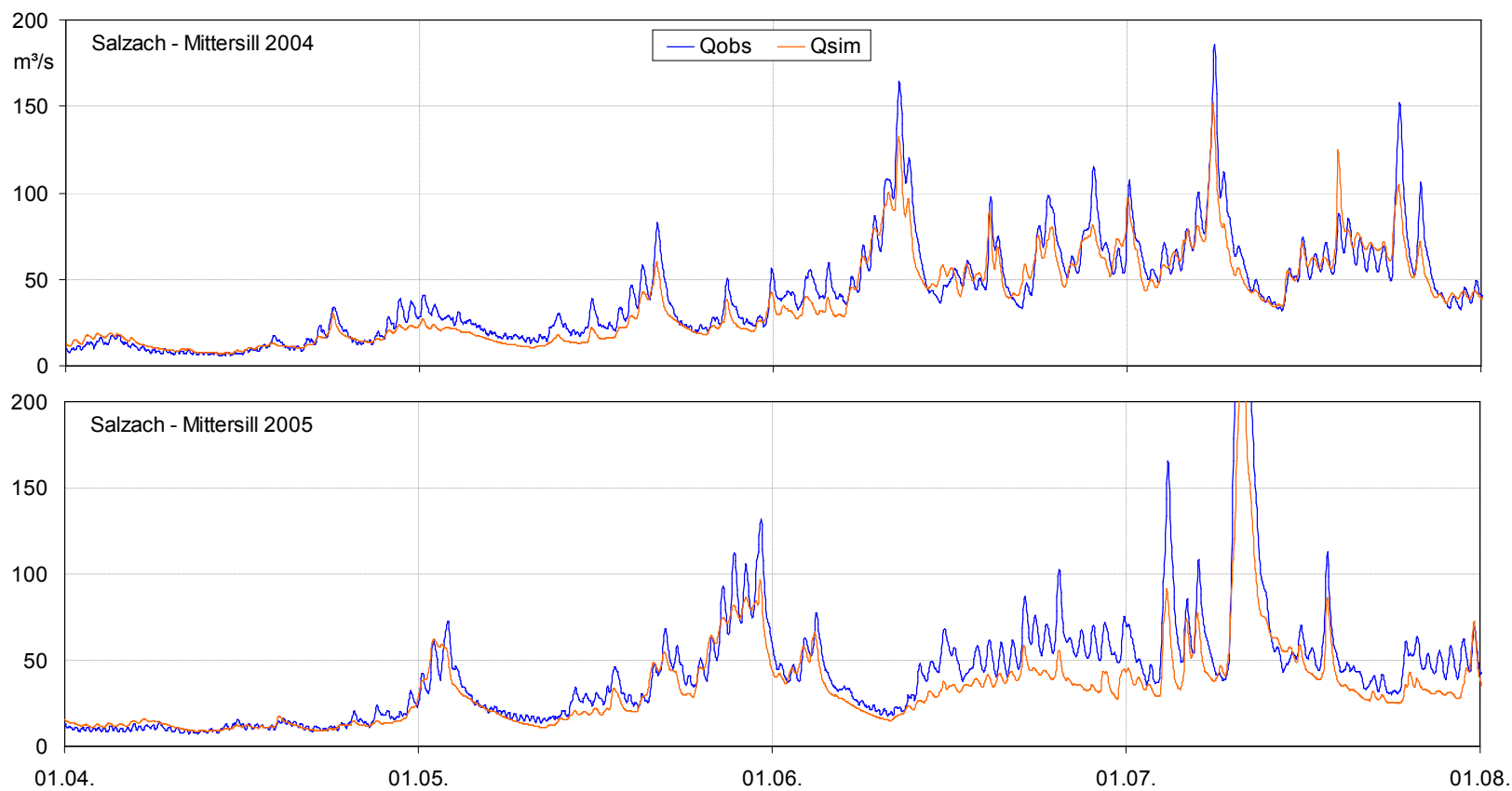

Figure 3: Runoff simulations and observations (April to July 2004 and 2005)

The course in time of snow accumulation matches very well. The start of the melting period and the sharp initial decrease of snow depth were reproduced correctly. In the later phase of ablation, however, simulated snow depth decreased slower than measured snow depth, resulting in a later end of snow cover.

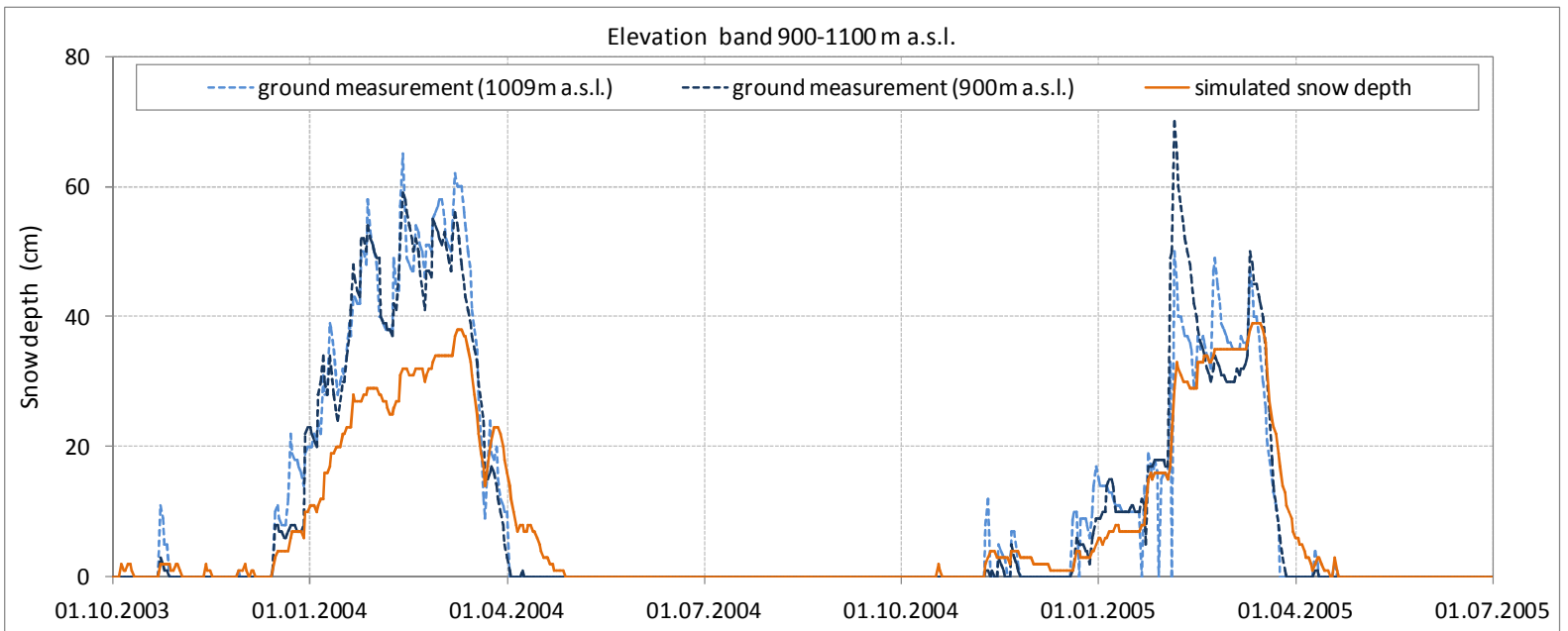

Figure 4: Snow depth simulations (elevation band $900-1100 \mathrm{~m}$ a.s.l.) and observations

Figure 5 shows a comparison of simulated snow covered area and results of analysing MODIS snow cover images for all elevation bands. The temporal characteristics of decreasing snow cover in the ablation period were generally reproduced. For the period from 30.04.2004 to 17.06.2004 simulated snow covered area was overestimated. For the period of 15.03.2005 to 02.05.2005 simulations and MODIS observations matched much better (the low values for higher elevations on 
15.03.2005 are due to cloud interference). Although results of two different years cannot directly be connected this corresponds with the finding that the earlier ablation phase, evaluated in March and April 2005, is reproduced better than the later ablation phase, evaluated in May and June 2004. This agreement with the results of the evaluation with ground measurements confirms that MODIS snow cover maps can be used in similar evaluations when little or no observations in higher altitudes are available.

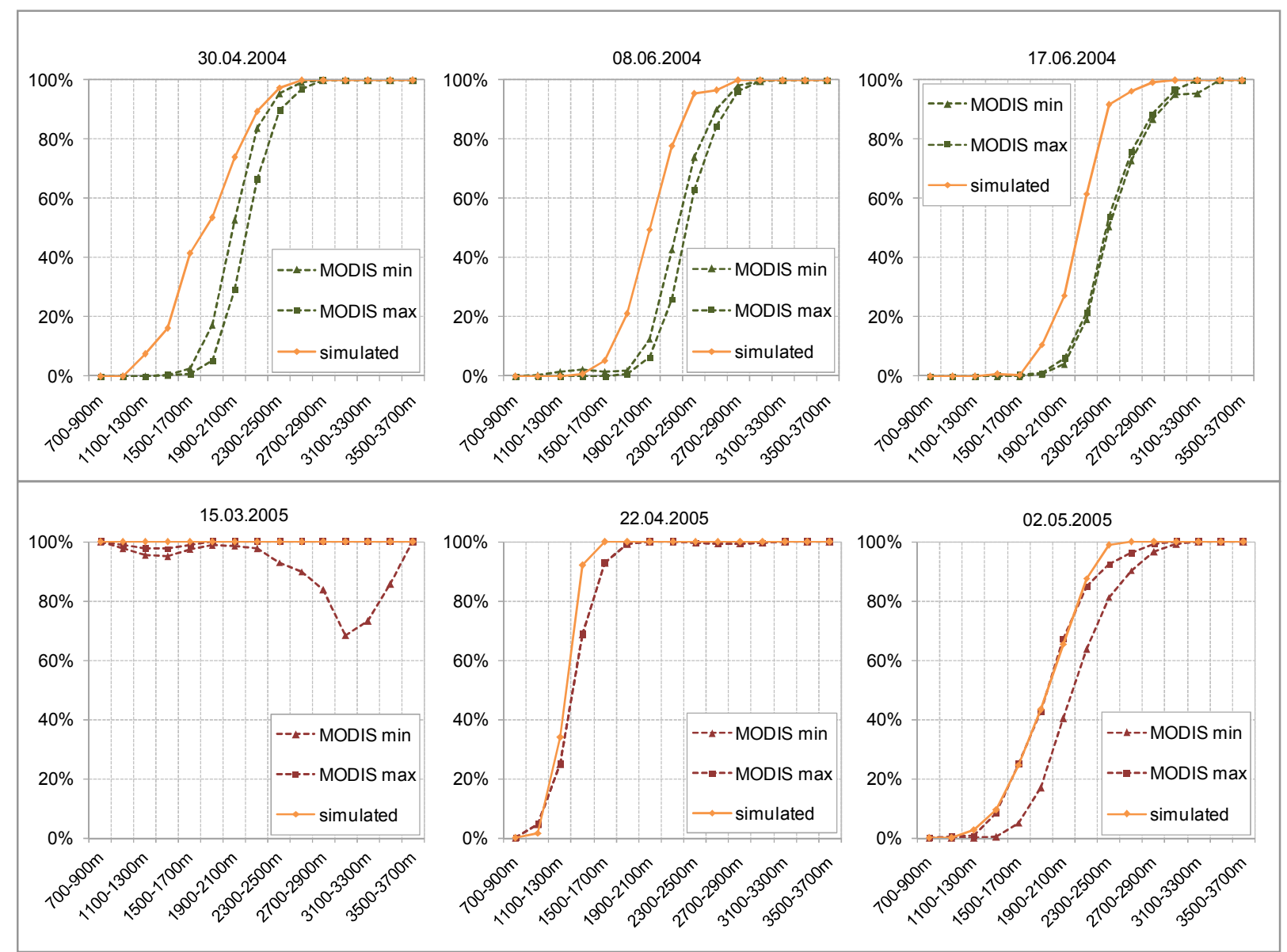

Figure 5: Snow covered area simulation and observations in ablation periods in 2004 and 2005

\subsection{Multi-objective recalibration}

First tests of manually recalibrating the snow model taking both runoff and snow information into account were performed. The objective with regard to snow modelling was to achieve a better representation of the duration of snow cover. With minor decreases of model performance with regard to runoff, faster melt in later ablation phases could be obtained when model parameters were altered beyond previous constraints. An evaluation whether this leads to more robust simulations will be carried out with results of the operational test during 2008. Effects of such recalibration on simulated runoff in the periods of largest contributions of snow melt to floods (May and June) were very low. 


\section{CONCLUSIONS}

Snow modelling results of a hydrological model using only precipitation and temperature as input data were evaluated. In addition to discharge measurements snow depth measurements and MODIS remote sensing snow cover information were compared to simulation results.

The model was able to simulate the seasonal runoff variations due to snow melt very well. The analyses of simulated snow depths and snow covered area showed strengths and limitations of the model and supported assessment of input data quality. The effect of improving snow cover modelling results on the simulation of flood runoff with high snow melt contributions was very low.

MODIS snow cover maps allowed an evaluation of snow modelling for the whole range of elevations and for the whole ablation period. Good agreement with results of model evaluation with snow depth ground measurements showed that MODIS snow cover images are a valuable source of information in alpine areas, where ground observations are scarce.

\section{ACKNOWLEDGEMENTS}

The ongoing research has been carried out in the framework of a project funded by the Provincial Government of Salzburg, VERBUND-Austrian Hydro Power AG and Salzburg AG.

Data was provided by these institutions, the Federal Ministry of Agriculture, Forestry, Environment and Water Management and the Central Institute for Meteorology and Geodynamics (ZAMG).

\section{References}

Fuchs M. (1998): Modeling snow-melt runoff in an alpine watershed. Master thesis, Institute of Water Management, Hydrology and Hydraulic Engineering, University of Natural Resources and Applied Life Sciences, Vienna, Austria.

Haiden, T., A. Kann, K. Stadlbacher, M. Steinheimer, und C. Wittmann (2007): Integrated Nowcasting through Comprehensive Analysis (INCA) - System overview. ZAMG report.

Hall, D. K., Riggs G. A., and Salomonson V. V. (2006): MODIS/Terra snow cover daily L3 global 500m grid V005, 30.04., 08.06, 17.06.2004; 15.03., 22.04., 02.05.2005. Boulder, Colorado USA: National Snow and Ice Data Center. Digital media.

Kling H. (2006): Spatio-temporal modelling of the water balance of Austria. Dissertation, Institute of Water Management, Hydrology and Hydraulic Engineering, University of Natural Resources and Applied Life Sciences, Vienna, Austria.

Parajka, J and Blöschl, G. (2006): Validation of MODIS snow cover images over Austria. Hydrol. Earth Syst. Sci., 10, 679-689.

Nachtnebel H.P., Baumung S., Lettl W. (1993). Abflussprognosemodell für das Einzugsgebiet der Enn und Steyr (in German). Report, Institute of Water Management, Hydology and Hydraulic Engineering, University of Natural Resources and Applied Life Sciences Vienna, Austria. 